Research Article

\title{
FEA of Effects Induced by Diurnal Temperature Variation on Downstream Surface of Xiaowan Arch Dam
}

\author{
Huanhuan Li $\mathbb{D},{ }^{1}$ Shaojun Fu $\mathbb{D},{ }^{2}$ Gang Li $\mathbb{D},{ }^{1}$ and Guofei Hu $\mathbb{D}^{3}$ \\ ${ }^{1}$ Shaanxi Key Laboratory of Safety and Durability of Concrete Structures, Xijing University, Xi'an, China \\ ${ }^{2}$ School of Civil Engineering, Wuhan University, Wuhan, China \\ ${ }^{3}$ Anhui Institute of Building Research and Design, Hefei, China \\ Correspondence should be addressed to Shaojun Fu; sgjg@whu.edu.cn
}

Received 18 April 2021; Accepted 19 June 2021; Published 30 June 2021

Academic Editor: Chi Yao

Copyright $\odot 2021$ Huanhuan Li et al. This is an open access article distributed under the Creative Commons Attribution License, which permits unrestricted use, distribution, and reproduction in any medium, provided the original work is properly cited.

In order to make clear the cracking reasons in arch dam of Xiaowan Hydropower Station during operation period, the approach to combine ANSYS with finite element program COCE-3D is adopted. Firstly, the influence by element type and mesh size for the temperature field simulation result is analyzed. Subsequently, the three typical dam segments cut from Xiaowan arch dam are selected and the relevant finite element model is established; the effect of the measured diurnal air temperature on temperature field and temperature stress of arch dam is analyzed thoroughly. The results indicate that the temperature gradient in mass concrete becomes lower, whereas the affecting depth becomes deeper when the mesh size is too large. Therefore, it is advisable to use smaller size mesh to study the influence of the measured diurnal air temperature on the surface temperature distribution in mass concrete. The temperature of downstream zone in arch dam is significantly affected by air temperature; the changing laws of temperature field and temperature stress with the air temperature are basically consistent, which is sensitive to lower temperature. When the temperature sharply decreased, the temperature stress in the downstream zone is mainly in tensile stress state. The calculated results are basically consistent with the measured results, and the temperature stress induced by the day-night temperature difference is the important reason for the horizontal cracks on the downstream surface. The submodel analysis method is an important alternative approach to study the changing laws of temperature field of arch dam. The research results not only provide an evidence for temperature control and crack prevention of Xiaowan arch dam but also provide a reference for temperature field simulation of similar projects.

\section{Introduction}

It is acknowledged that thermal load is one of the important reasons for concrete arch dam cracking, both during construction and operation [1-4]. During the construction, due to the exothermic reactions, a lot of hydration heat cannot be released in time, resulting in the increase of internal temperature gradient and thermal stress, which leads to cracks. It is usually controlled by cooling water pipes or lowering concrete pouring temperature. Due to the influence of external environment, the cracking of arch dam during operation is still a difficult problem $[5,6]$. As for the causes of cracks during the operation, Zhu proposed that the fundamental reason was that the influence of nonlinear temperature difference and cold wave was not considered in the calculation of temperature load. Furthermore, he proposed that permanent surface thermal insulation was an effective method to prevent cracks occurring in arch dams during operation [7]. Temperature cracks problem was an important research topic in the field of high arch dam structure. To date, lots of achievements [3] related to thermal stress and temperature cracks of concrete dams mainly are focused on the influence of the diurnal temperature variation during the construction $[8,9]$, and the annual temperature $[10]$, seasonal temperature variations $[4,11,12]$, solar radiation $[13,14]$, and water temperature variations [1] during the operation. The results show that the cold wave or the diurnal temperature variation will affect the thermal field within a certain range below the concrete surface and lead to the surface cracks [15]. 
Xiaowan hydropower station, which is located in the middle reach of the Lancang River, is primarily for power generation and can also make other comprehensive utilization benefits such as flood control. Xiaowan arch dam is a parabolic double-curvature concrete dam, with the dam crest elevation of $1245 \mathrm{~m}$, the maximum dam height of $294.5 \mathrm{~m}$, the arc length of the crest centerline of $892.8 \mathrm{~m}$, the bottom width of the crown cantilever of $69.49 \mathrm{~m}$, and the crest width of the crown cantilever of $13 \mathrm{~m}$. The dam includes 5 open surface spillways, 6 middle discharge holes, and 2 emptying bottom holes. During the service period of the arch dam, some horizontal and irregular cracks with different lengths are found on the arch dam downstream surface at the elevation of $1150 \mathrm{~m}$ to $1190 \mathrm{~m}$ through the field inspection. In order to find out the causes of cracks at the downstream side of Xiaowan arch dam, the temperature effect of concrete under the action of diurnal temperature variation is studied. It is necessary to establish a finite element model with smaller mesh size and select the calculation time step in hours. Due to the great difference between the size of the study area and that of the whole dam, it requires large computation scale and high request on computer hardware if establishing a finite element model for the whole dam. In order to better analyze the influence of the diurnal temperature variation on the thermal field and thermal stress field of the downstream-side concrete of Xiaowan arch dam, firstly, the sensitivity of element type and mesh size to the thermal field was analyzed. Subsequently, the 27\# 29\# typical segments of Xiaowan arch dam were taken as an example to establish 3-D finite element submodel, and the method of combining the whole model and the submodel [16] was adopted to simulate the changing law of thermal field and thermal stress field at the downstream side of arch dam under the action of diurnal temperature variation. Finally, the cause of cracks at downstream side of Xiaowan arch dam was revealed. It provides the guideline for temperature control and crack prevention of Xiaowan arch dam and reference for similar projects.

\section{Computational Principles of Thermal Field and Thermal Stress}

2.1. Thermal Field. According to the principle of thermal balance, the heat absorbed as the temperature rise is equal to the sum of the net heat flowing in from the outside and the heat of hydration inside. As for the isotropy, the basic equation of heat conduction in the 3-D transient thermal field is

$$
a\left(\frac{\partial^{2} T}{\partial x^{2}}+\frac{\partial^{2} T}{\partial y^{2}}+\frac{\partial^{2} T}{\partial z^{2}}\right)+\frac{\partial \theta}{\partial \tau}=\frac{\partial T}{\partial \tau},
$$

where $\theta$ is the adiabatic temperature rise of concrete $\left({ }^{\circ} \mathrm{C}\right)$, $\alpha=\lambda / c \rho, \lambda$ is the thermal conductivity of concrete $(\mathrm{kJ} /(\mathrm{m} . \mathrm{h}$. $\left.\left.{ }^{\circ} \mathrm{C}\right)\right), c$ is the specific heat of concrete $\left(\mathrm{kJ} /\left(\mathrm{kg} .{ }^{\circ} \mathrm{C}\right)\right), \rho$ is the concrete density $\left(\mathrm{kg} / \mathrm{m}^{3}\right)$, and $\tau$ is time $(h)$.

For (1), the unique solution can be obtained by introducing corresponding initial conditions and boundary conditions [17]. According to the variation principle, the governing equation of finite element can be derived:

$$
[H]\{T\}+\{F\}=0,
$$

where $[H]$ is the heat conduction matrix and $\{F\}$ is the thermal flow array.

2.2. Thermal Stress. From the elastomer hypothesis, it can be known that the coefficient of thermal expansion of a material is constant in all directions; that is to say, the positive strain does not change with direction or does not produce angular strain. Assuming the temperature variation on each node in the elastomer is $\Delta T$, the coefficient of thermal expansion is $\alpha$, and the produced free deformation is $\alpha \Delta T$, the corresponding initial strain arising therefrom shall be

$$
\left\{\varepsilon^{0}\right\}=\left\{\varepsilon_{x}^{0}, \varepsilon_{y}^{0}, \varepsilon_{z}^{0}, \gamma_{x y}^{0}, \gamma_{y z}^{0}, \gamma_{z x}^{0}\right\}=\alpha \Delta T\{1,1,1,0,0,0\}^{T} .
$$

The total strain of elastomer is composed of the strain generated by temperature difference and the strain generated by other stresses, so the stress-strain relationship shall be

$$
\{\sigma\}=[D]\left(\{\varepsilon\}-\left\{\varepsilon^{0}\right\}\right)=[D][B]\{\delta\}^{e}-[D]\left\{\varepsilon^{0}\right\} .
$$

And the relationship between node force and node displacement can be expressed as

$$
\{F\}^{e}=[K]^{e}\{\delta\}^{e}+\left[F_{\Delta T}\right]^{e},
$$

where $\{\sigma\}=\left\{\sigma_{x}, \sigma_{y}, \sigma_{z}, \tau_{x y}, \tau_{y z}, \tau_{z x}\right\}^{T} ;[D]$ is the elastic matrix of element; $[B]$ is the characteristic matrix of element; $\{\delta\}^{e}$ is the node displacement matrix of element; $[K]^{e}$ is the stiffness matrix of element; and $\left[F_{\Delta T}\right]^{e}=-\iiint_{e}[B]^{T}[D]\left\{\varepsilon^{0}\right\} \mathrm{d} x \mathrm{~d} y \mathrm{~d} z$ is the equivalent nodal load generated by temperature variation.

\section{Basic Information of the Project}

3.1. Daily Temperature of Dam Site. According to the air temperature measured at the weather station (hourly variation), the process of temperature changes in the winter of 2014 (from $14 \mathrm{~h}$ on January 24 to $14 \mathrm{~h}$ on January 28) and in the summer of 2013 (from $14 \mathrm{~h}$ on June 11 to $14 \mathrm{~h}$ on June 15 ) is shown in Figure 1, where the maximum diurnal temperature variation is $19^{\circ} \mathrm{C}$.

3.2. Water Temperature of the Reservoir. The normal impounding water level of Xiaowan is $1240 \mathrm{~m}$ during operation, and the water level of the corresponding downstream plunge pool is $1004 \mathrm{~m}$. The average annual water temperature on the surface of Xiaowan reservoir is $20.6^{\circ} \mathrm{C}$, and the annual amplitude of the water temperature on the surface (including the influence of sunlight) is $6.0^{\circ} \mathrm{C}$. The water temperature under the elevation of $1120 \mathrm{~m}$ is constant at $10^{\circ} \mathrm{C}$, while the water temperature in the elevation range from $1120 \mathrm{~m}$ to $1240 \mathrm{~m}$ is computed according to the following equations [17]: 


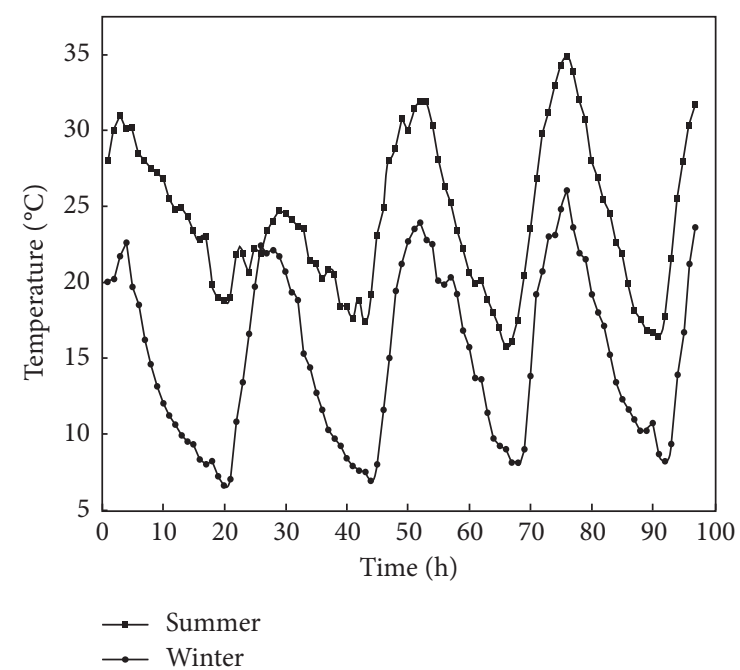

FIgURE 1: Temperature variation chart of typical time period.

$$
\begin{aligned}
& T(y, t)=T_{m}(y)+A_{0} e^{-0.048 y} \cos \omega\left(t-t_{0}-\varepsilon\right), \\
& T_{m}(y)=\frac{T_{b}-T_{s} e^{-0.04 H}}{1-e^{-0.04 H}}+\left(T_{s}-\frac{T_{b}-T_{s} e^{-0.04 H}}{1-e^{-0.04 H}}\right) e^{-0.04 y},
\end{aligned}
$$

where $T(y, t)$ is the temperature at depth $y$ at time $t\left({ }^{\circ} \mathrm{C}\right) ; A_{0}$ is the average of the difference values of the monthly maximum and minimum temperatures; $\omega$ is the cycle of daily temperature change, taking $\pi / 12 ; \varepsilon$ is the phase difference between water temperature and air temperature; $T_{\mathrm{b}}$ is the average annual water temperature at the bottom of the reservoir $\left({ }^{\circ} \mathrm{C}\right)$, taking $10^{\circ} \mathrm{C} ; T_{\mathrm{s}}$ is the monthly air temperature on the surface plus the sunlight $\left({ }^{\circ} \mathrm{C}\right) ; t$ is the time when the calculation conducted $(\mathrm{h}) ; t_{0}$ is the time of the highest temperature $(\mathrm{h})$, generally taking $14 \mathrm{~h} ; H$ is the reservoir depth $(\mathrm{m})$; and $y$ is the water depth $(\mathrm{m})$.

3.3. Thermodynamic Property of Dam Concrete. The dam concrete was divided into A, B, and C; these three zones and the thermal and mechanical parameters of concrete could be found in Table 1.

\section{Analysis Models and Analysis Methods}

4.1. Sensitivity Analysis of Element Type and Mesh Size. The simulated calculation of thermal field [20] showed that the element type and mesh scale significantly influenced the precision of computation results. In general, to the mesh scale with the same element type, if the mesh scale is large, the calculation precision is low. Otherwise, the calculation precision is high but the efficiency is low. Therefore, the complex engineering problems could not even be realized on a microcomputer. Therefore, to investigate the influence of the element type and the mesh scale on the precision of simulating results of concrete thermal field, especially the influence of the external air temperature on the gradient of thermal field in the surface region of concrete, a simple example should be first established to analyze the sensitivity of mesh scales and element types to the precision of computation.

To a rectangle model with size of $2 m \times 2 m \times 4 \mathrm{~m}$, two element types and three mesh scales were adopted discretely (as shown in Table 2). $\mathrm{C}_{180} 40$ is taken as the thermal parameter, the initial temperature is the uniform temperature of $20^{\circ} \mathrm{C}$, and the air temperature boundary is the winter temperature curve as shown in Figure 1.

Figure 2 shows the cloud chart of the thermal field of above four schemes at $20 \mathrm{~h}$. From Figure 1, it could be known that the air temperature at $20 \mathrm{~h}$ is $6.6^{\circ} \mathrm{C}$, so by comparing the four schemes, the results are shown such that the range of temperature gradient of scheme 1 and scheme 4 is $12.8^{\circ} \mathrm{C}-20^{\circ} \mathrm{C}$, and the influence depth is about $0.35 \mathrm{~m}$. The temperature variation range of scheme 3 is $16.1^{\circ} \mathrm{C}-20^{\circ} \mathrm{C}$, and the influence depth is about $0.8 \mathrm{~m}$, roughly twice as much as options 1 and 2. Scheme 4 has the same temperature variation range as that in schemes 1 and 2 and has the same influence depth of air temperature as that in scheme 3 .

Figure 3 is the temperature course curves of a node on the external surface of the models in four schemes. From Figure 3, it could be known that the trend and amplitude of temperature variations of schemes 1,2 , and 4 are the same, while the amplitude of temperature variation of scheme 3 is smaller and its peak time obviously lags behind that of its peak time of air temperature.

In conclusion, we have the following: (1) The temperature distribution law and the variation process of schemes 1 and 2 are consistent with the understanding of relevant literatures $[1,15]$. (2) When the element type is the same, if the mesh size is too large, the surface temperature range of concrete is small, and the calculated value of temperature influence depth is large. (3) When the mesh size is the same, the calculation precision of surface temperature could be improved by using the high-order element, but the precision of the influence range is not improved. Therefore, an 8-node hexahedral element is applied in the paper, and the element scale in the direction of dam thickness is controlled within the range of $0.1 \mathrm{~m}-0.5 \mathrm{~m}$.

4.2. Finite Element Mesh. By considering the element with small scale and its computation scale, $27^{\#} \sim 29^{\#}$ dam segments of Xiaowan arch dam were selected as research objects (as shown in Figure 4(a)) to be conducted discretely by using 8 -node hexahedral element. The element scale in the direction of dam thickness was controlled within $0.1 \mathrm{~m}-0.5 \mathrm{~m}$, while the element scales in vertical direction and at right angle were controlled at about 10 times the element scale in the direction of thickness. The finite element mesh of submodels was shown in Figure 4(b), with total elements of 669,960 and with total nodes of 721,315 .

4.3. Initial Conditions and Boundary Conditions. For stress and strain analysis, it was agreed in the coordinate system that the $X$-axis pointing to the left bank was positive, the $Y$ axis pointing to the upstream was positive, and the $Z$-axis upwards was positive. 
TABLE 1: Thermal and mechanical parameters of dam concrete.

\begin{tabular}{|c|c|c|c|c|}
\hline \multicolumn{5}{|c|}{ Concrete grade } \\
\hline Parameter & & $\mathrm{C}_{180} 40$ & $\mathrm{C}_{180} 35$ & $\mathrm{C}_{180} 30$ \\
\hline Thermal conductivity & $\mathrm{kJ} /\left(\mathrm{m} \cdot \mathrm{h}^{\circ} \mathrm{C}\right)$ & 8.479 & 8.227 & 8.016 \\
\hline Thermal diffusivity & $\mathrm{m}^{2} / \mathrm{h}$ & 0.003239 & 0.003116 & 0.002991 \\
\hline Density & $\mathrm{kg} / \mathrm{m}^{3}$ & & 2500 & \\
\hline Specific heat & $\mathrm{kJ} /\left(\mathrm{kg}^{\circ} \mathrm{C}\right)$ & 1.047 & 1.056 & 1.072 \\
\hline Coefficient of linear expansion & $10^{-6} /{ }^{\circ} \mathrm{C}$ & 8.26 & 8.15 & 8.1 \\
\hline Heat exchange coefficient & $\mathrm{kJ} /\left(\mathrm{m}^{2} \cdot \mathrm{h}^{\circ} \mathrm{C}\right)$ & & 47.1 & \\
\hline Elasticity modulus & $10^{4} \mathrm{MPa}$ & 3.21 & 3.11 & 3.01 \\
\hline Poisson's ratio & & 0.24 & 0.167 & 0.167 \\
\hline Compressive strength & $R_{\mathrm{a}} / \mathrm{MPa}$ & 45.5 & 39.7 & 34.4 \\
\hline Tensile strength & $R_{\mathrm{l}} / \mathrm{MPa}$ & 3.52 & 3.36 & 3.07 \\
\hline Safety factor against cracking on the surface $[18,19]$ & & & $1.4-1.5$ & \\
\hline
\end{tabular}

TABle 2: Element types and mesh sizes.

\begin{tabular}{lcc}
\hline Scheme & Element type & Mesh size (in the direction of thickness) (m) \\
\hline 1 & 8-node hexahedral element & 0.1 \\
2 & 8-node hexahedral element & 0.2 \\
3 & 8-node hexahedral element & 1 \\
4 & 20-node hexahedral element & 1 \\
\hline
\end{tabular}

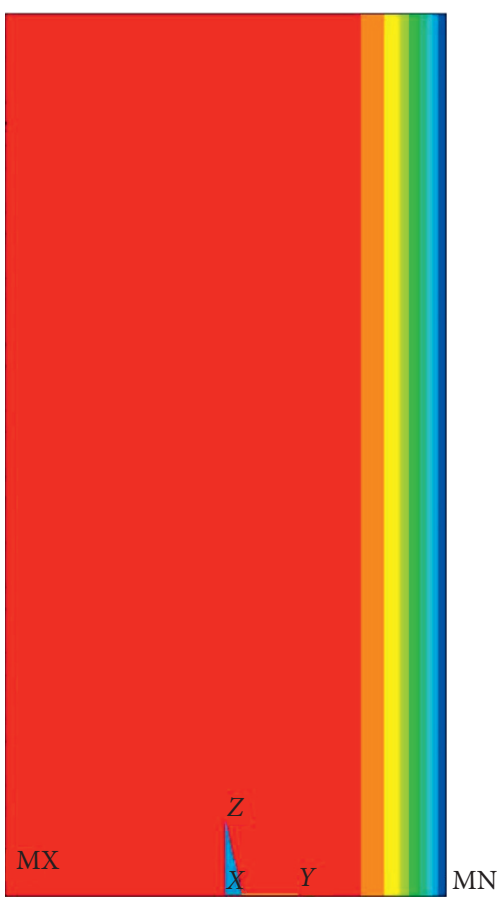

(a)

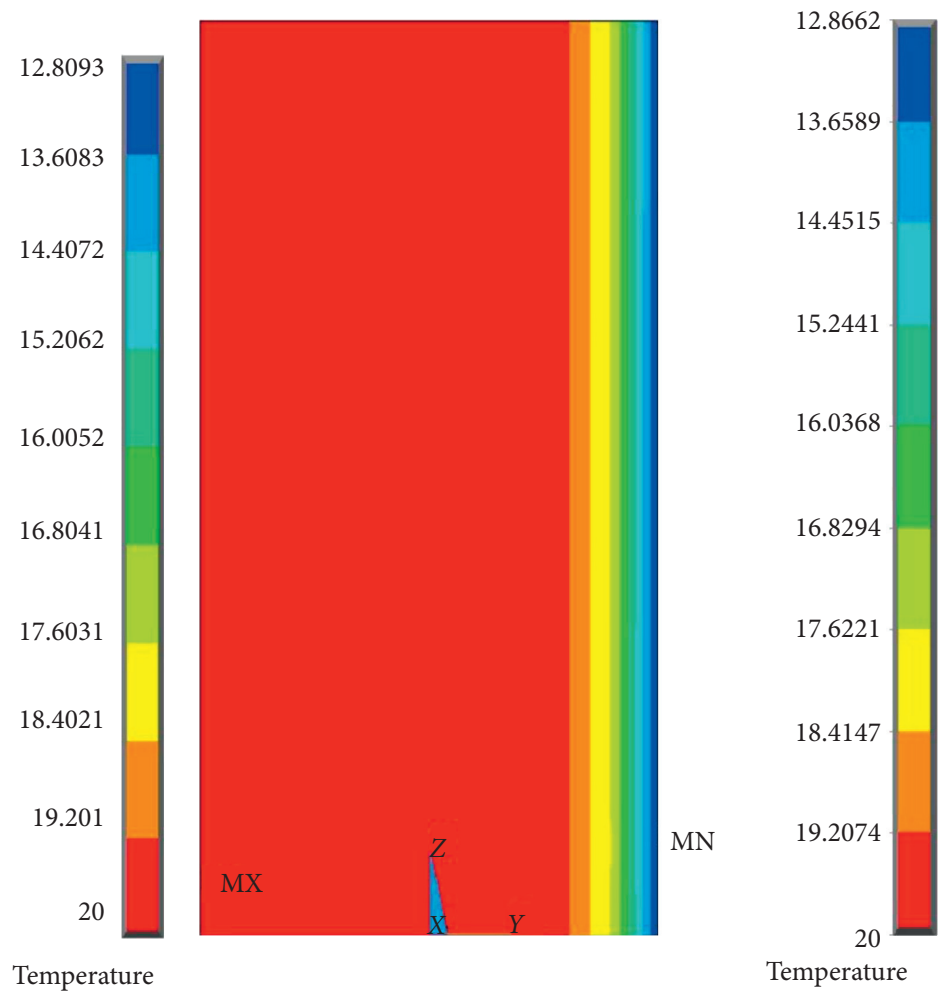

(b)

Figure 2: Continued. 


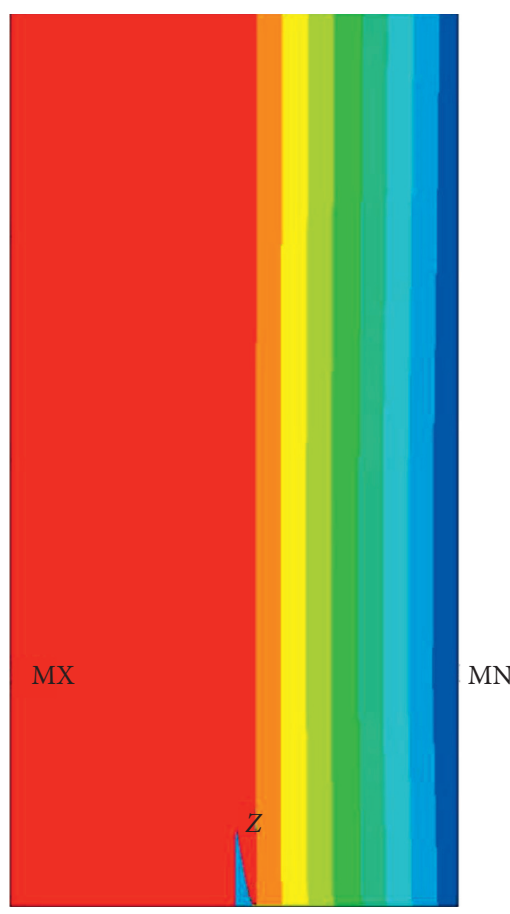

(c)

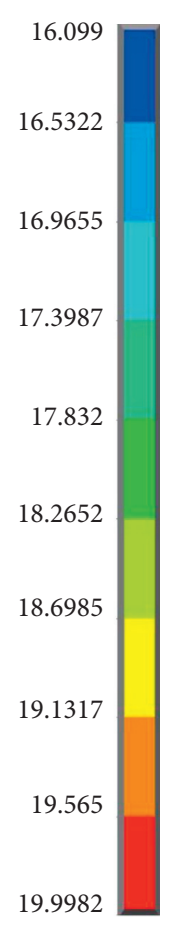

Temperature

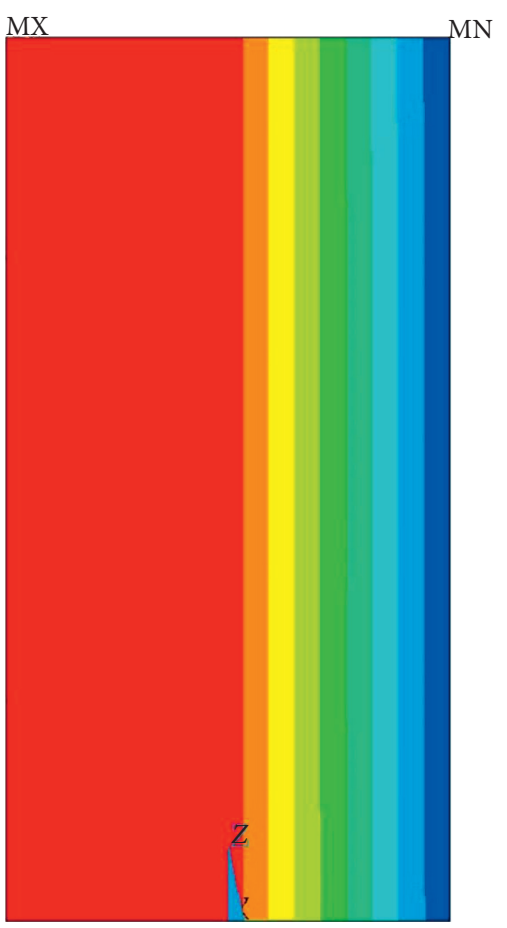

(d)

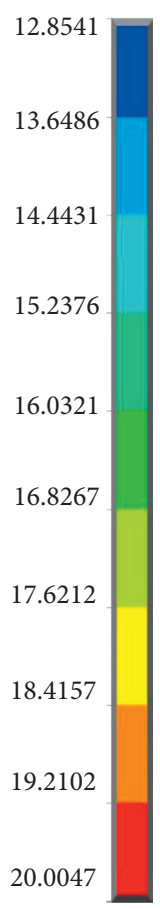

Temperature

Figure 2: Cloud chart of thermal field at $20 \mathrm{~h}$. (a-d) Temperature.

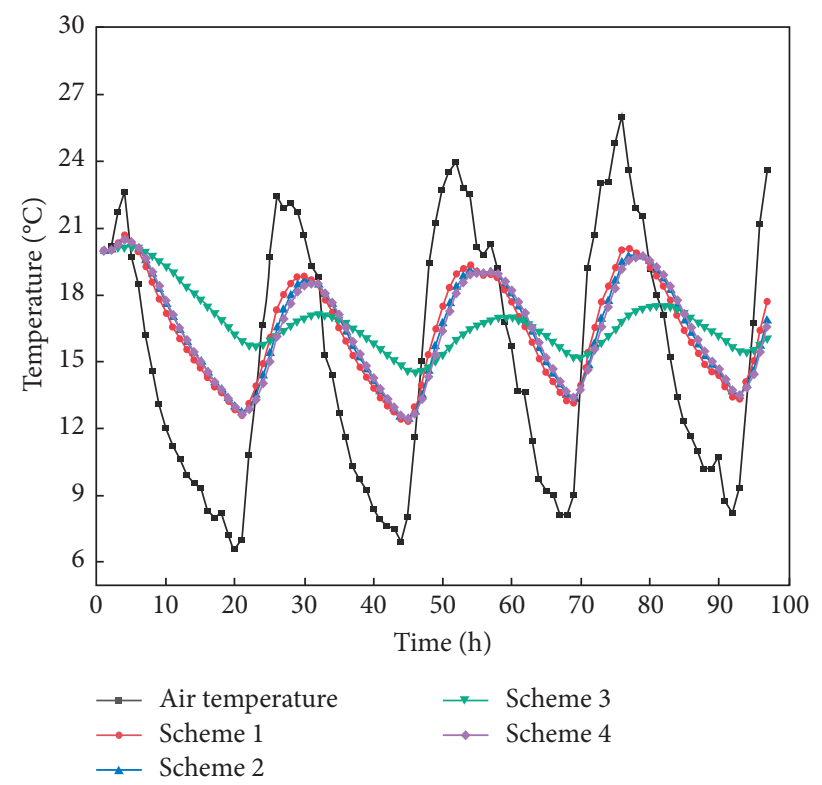

Figure 3: Temperature course curves of a node on outside surface.

Boundary conditions: in the computation of thermal field, the water temperature at the boundary between the dam and water was taken according to the first boundary condition, and the boundary between the dam and air was selected according to the third boundary condition, while the bottom and two sides of the foundation were treated according to the adiabatic condition. And in the computation of stress field, the bottom of the foundation was fixed, the four sides of the foundation and the two sides of the dam were normal constraints, and the rest were free surfaces.

Initial conditions: for thermal field analysis, the diurnal temperature variation of typical days in winter and summer was investigated, respectively. According to the measured 


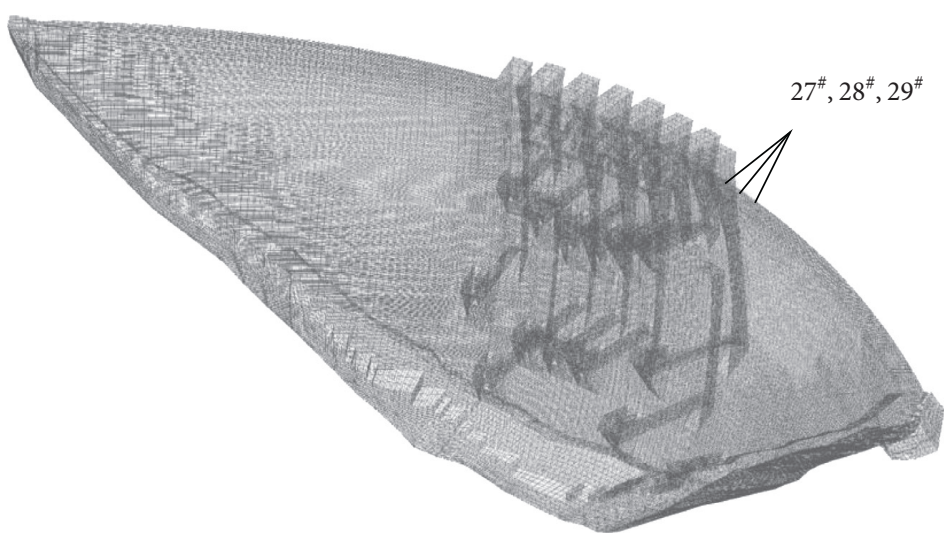

(a)

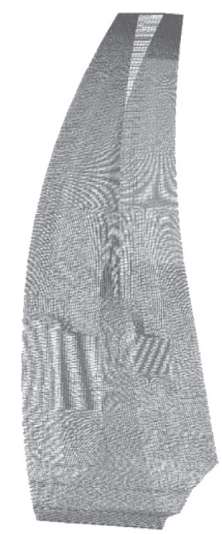

(b)

Figure 4: Finite element mesh of Xiaowan arch dam: (a) the whole model and (b) the submodel.

data, the time from 14:00 on January 24 to 14:00 on January 28 of 2014 was selected as winter period and the time from 14:00 on June 11 to $14: 00$ on June 15 of 2013 was selected as summer period. The thermal fields corresponding to $14: 00$ on January 24 of 2014 and 14:00 on June 11 of 2013 were respectively served as the initial condition. Since the stress-strain analysis only considered the increment caused by the diurnal temperature difference, the initial stress field was set as 0 .

\subsection{Analysis Methods}

4.4.1. Thermal Field Analysis. The arch dam was closed by grouting to the dam crest on June 11, 2010, and by 2013, the internal temperature of the dam was stabilized and the temperature on the dam surface was mainly influenced by the external air temperature and the reservoir water temperature. In view of the calculation scale of the simulated analysis of thermal field for the whole dam section and the whole process, the mesh scale was larger than $1 \mathrm{~m}$, and the time step was "day". Therefore, when the results of the simulated analysis of thermal field for the whole dam section and the whole process were applied to analyze the effect of diurnal temperature variation of precise submodels (the time step was "hour"), the initial temperature conditions should be properly treated. And the effect of diurnal temperature variation on January 26, 2013 and June 13, 2014 was investigated respectively as winter and summer periods, so the initial value of node temperature of $27^{\#} \sim 29^{\#}$ finite element mesh models could be obtained through the interpolation of the simulated analysis results of the whole dam section and the whole process in the thermal fields at 14:00 on January 24, 2013 and June 11, 2014. Subsequently, the boundary conditions of daily air temperature and water temperature were applied to $27^{\#} \sim 29^{\#}$ submodels for simulated calculation, with 2 days apart from January 26, 2013 and June 13,2014, respectively, not having obvious influence on the precision of typical daily thermal field results.

ANSYS software was applied to analyze the thermal field, with total computation time of 4 days, time step as "hour", and 96 computation steps in total. The initial conditions should be set according to the methods mentioned above, and the boundary conditions of air temperature and water temperature were simulated according to Sections 3.1 and 3.2 .

4.4.2. Stress-Strain Analysis. This paper focused on the state of incremental stress generated by the diurnal temperature variation, so as to explain the possibility of cracking caused by the diurnal temperature variation. Therefore, the linear elastic finite element calculation was carried out on $27^{\#} \sim 29^{\#}$ dam section models by considering the action of diurnal temperature variation, and the concrete was considered as a homogeneous isotropic elastomer.

The calculation of period and step length kept consistent with that of thermal field, and the temperature action was the difference between the simulated calculation of the thermal field results at a certain time and that at the previous time, and so on. The incremental method was adopted to calculate the stress and strain. Since the concrete pouring had been finished for about 3-4 years and the analysis time was short, the creep was not taken into account.

Self-developed finite program COCE-3D was adopted for the finite element calculation of stress-strain, the program was successfully applied in many large-scale hydropower projects such as the Three Gorges hydropower station, Longtan hydropower station, Xiluodu hydropower station, and Xiaowan hydropower station, [21, 22].

\section{Results}

5.1. Result Analysis of Thermal Field. For the convenience of analyzing, two points $P 1$ and $P 2$ at the downstream side of the dam were selected, where $P 1$ was located at the downstream side with elevation of $1190 \mathrm{~m}$ and $P 2$ was located at the downstream side with elevation of $1150 \mathrm{~m}$, as shown in Figure 5.

Figure 6 shows the temperature-time curves of the two representative points, from which we could know the following: (1) The temperature on the downstream surface was significantly influenced by the air temperature variation, and its variation law was consistent with that of air temperature, 


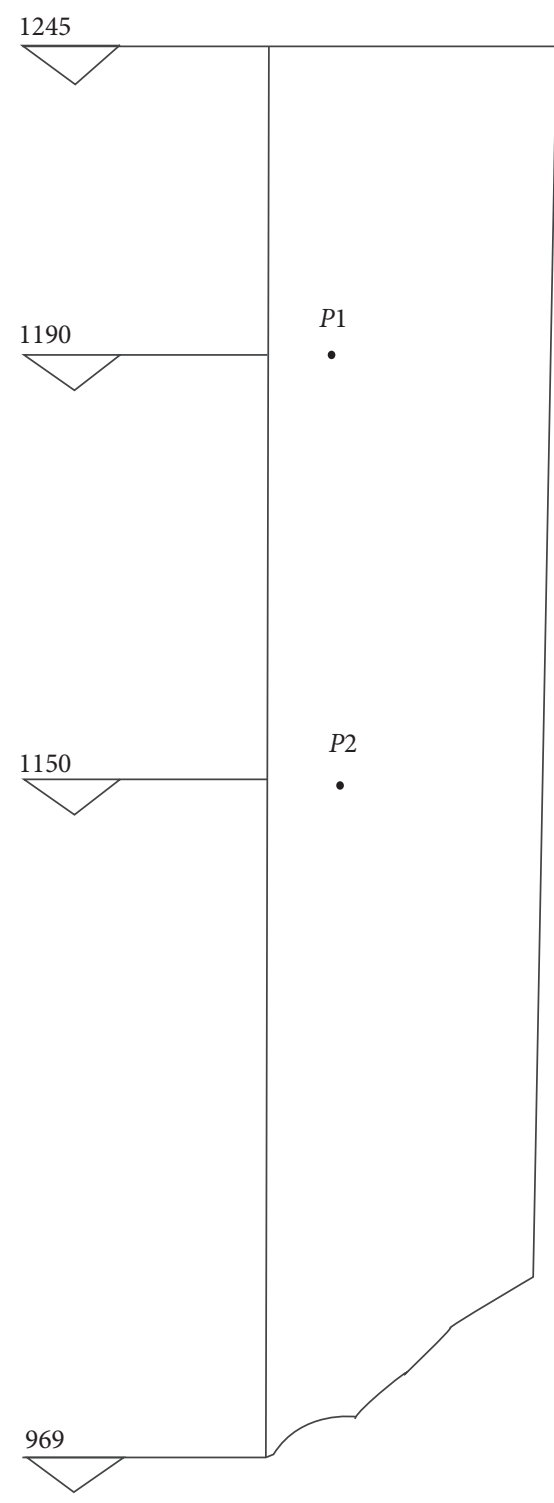

FIGURe 5: Position of representative points.

presented as a cosine curve, but the peak time of the dam surface temperature had an obvious hysteresis effect compared with that of the air temperature, about 2 hours lagging behind. This is consistent with the research rule in reference $[1,23]$. (2) Under the same action of air temperature variation law, values of temperature variation at $P 1$ and $P 2$ were basically consistent with the variation law. (3) The temperature gradient of concrete surface was affected more obviously by the change of diurnal temperature variation in winter.

Figure 7 shows the temperature curves of two typical time periods in the direction of dam thickness, where 4 moments $(24 \mathrm{~h}, 48 \mathrm{~h}, 72 \mathrm{~h}$, and $96 \mathrm{~h}$ ) were listed for each season. The compute node was taken every $0.15 \mathrm{~m}$ from the surface to the inside. From Figure 7, it could be found that a curve near the surface had a larger slope, which indicated that the temperature gradient in the region of this part was larger, and the air temperature had greater influence on the concrete of this part. When the distance reached a certain depth, the slope of curve was very small, almost developing into a straight line, which showed that the temperature gradient in the deep region was very small, and air temperature changes had little influence on it; the influence law is consistent with reference $[14,24,25]$. In the region where the temperature gradient had larger changes, and if the distance kept unchanged, as the computation time increased, the slope of curve decreased; for example, the slope of temperature curve at $24 \mathrm{~h}$ was larger than that at $96 \mathrm{~h}$, which explained that the shorter the action time of temperature changes, the larger the temperature gradient in the affected region.

When the influence depth of air temperature changes on concrete temperature was taken into consideration, the corresponding influence depth could be determined according to the difference of internal temperature variation amplitude; for example, the internal temperature variation was considered as $0.1,0.05$, and 0.01 times of the surface 


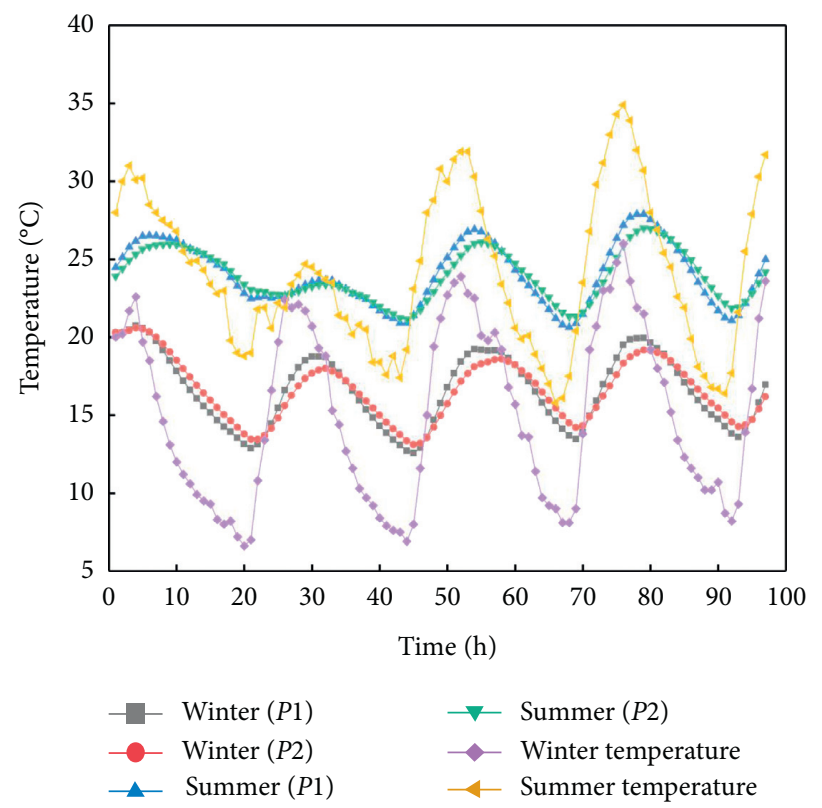

FIgURE 6: Temperature-time curves of two representative points at typical time.

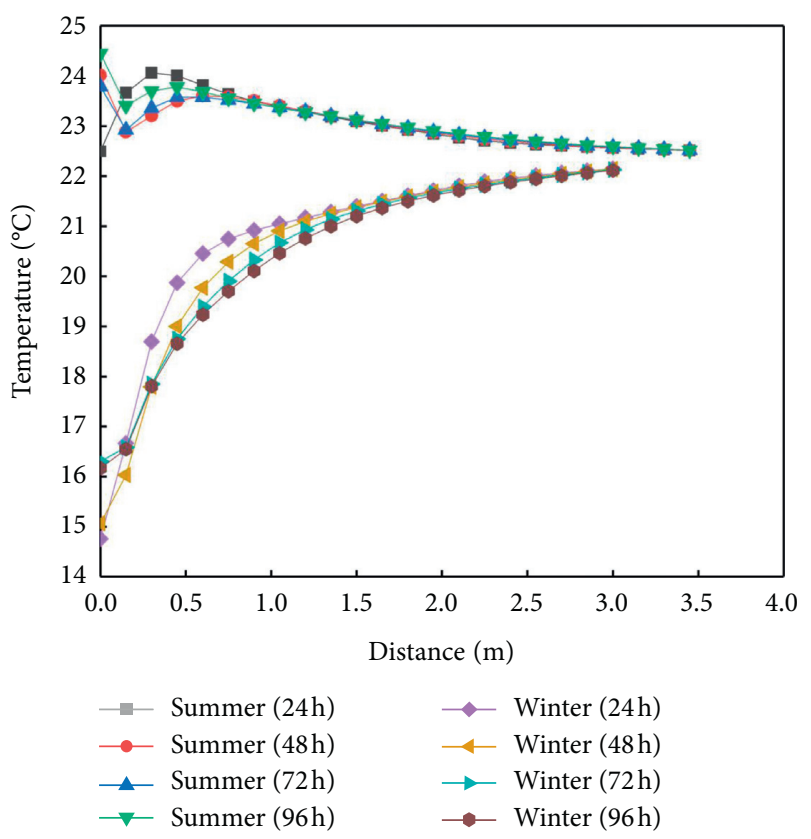

Figure 7: Temperature curves of typical time periods in the direction of dam thickness.

temperature variation amplitude of concrete. The influence depth of temperature at each condition is shown in Table 3, from which it could be known that the influence depth of temperature in winter was larger than that in summer.

In summary, the following conclusions could be drawn: (1) Air temperature changes in winter had greater influence on the thermal field of concrete; in other words, the concrete had sensitive temperature changes to temperature drop, a similar conclusion was obtained in reference [15]. (2) The longer the action time of the temperature difference, the greater depth of concrete affected by the temperature, but to be kept unchanged after reaching a certain depth. (3) The shorter the action time of the temperature difference, the greater the change of temperature gradient of concrete surface in a certain range.

5.2. Result Analysis of Thermal Stress. According to the observation, the cracks at the downstream side of Xiaowan arch dam were mostly horizontal; therefore, the maximum main stress and changes of thermal stress in the $Z$ direction were mainly discussed in this paper. Figure 8 shows the cloud charts of the maximum principal stress and the $Z$ direction stress at $68 \mathrm{~h}$ in winter (the external temperature of $8.1^{\circ} \mathrm{C}$ ). From Figure 8, it could be known that the maximum principal stress and the $Z$-direction stress were almost the same in size and direction, both of which were tensile stress. Figure 9 shows the cloud charts of the maximum principal stress and the $Z$-direction stress at $76 \mathrm{~h}$ in winter (the external temperature of $23.6^{\circ} \mathrm{C}$ ). From Figure 9, it could be known that the maximum principal stress and $Z$-direction stress were almost the same in size and direction, and a compressive stress appeared. The typical times in summer also had the similar laws, so it was not described in this paper.

Figure 10 shows the time curves of the normal stress in the $Z$-direction obtained at two representative points in two typical periods. From Figure 10, it could be known that the change law of $Z$-direction stress-time curves of the arch dam at $P 1$ and $P 2$ was consistent with that of temperature-time curves, both of which varied as cosine curve, which indicated that the stress state of concrete was greatly affected by the air temperature. The same rule was found in reference [23]. The $Z$-direction stress calculation results of both points at special moments are shown in Table 4.

In conclusion, under the action of diurnal temperature difference in winter, concrete at the downstream of arch dam 
TABLE 3: Influence depth of air temperature.

\begin{tabular}{lcccc}
\hline & & \multicolumn{2}{c}{ Time period } \\
Times of surface temperature variation amplitude & & Winter & $96 \mathrm{~h}$ & $24 \mathrm{~h}$ \\
\hline 0.1 & $24 \mathrm{~h}$ & 0.6 & 0.3 & $0.4 \mathrm{~h}$ \\
0.05 & 0.45 & 0.75 & 0.45 & 1.65 \\
0.01 & 1.2 & 1.5 & 1.2 \\
\hline
\end{tabular}

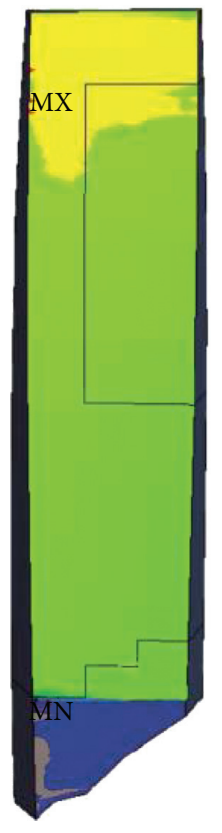

(a)
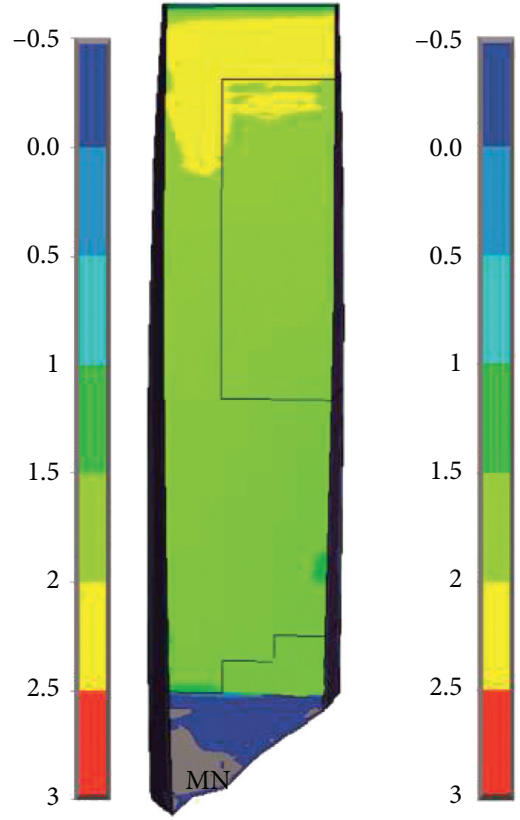

(b)

FIGURE 8: Stress contour at the downstream side of Xiaowan arch dam in winter (68 h): (a) the maximum principal stress and (b) the $Z$ direction stress.
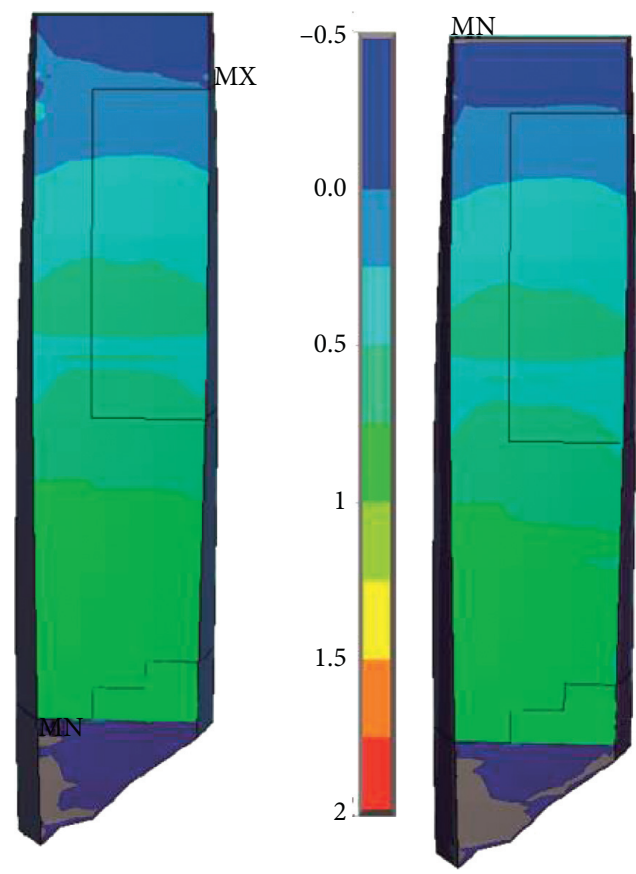

(b)

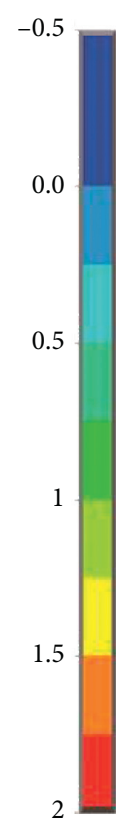

(a)

Figure 9: Stress contour at the downstream side of Xiaowan arch dam in winter (76h): (a) the maximum principal stress and (b) the $Z$ direction stress. 


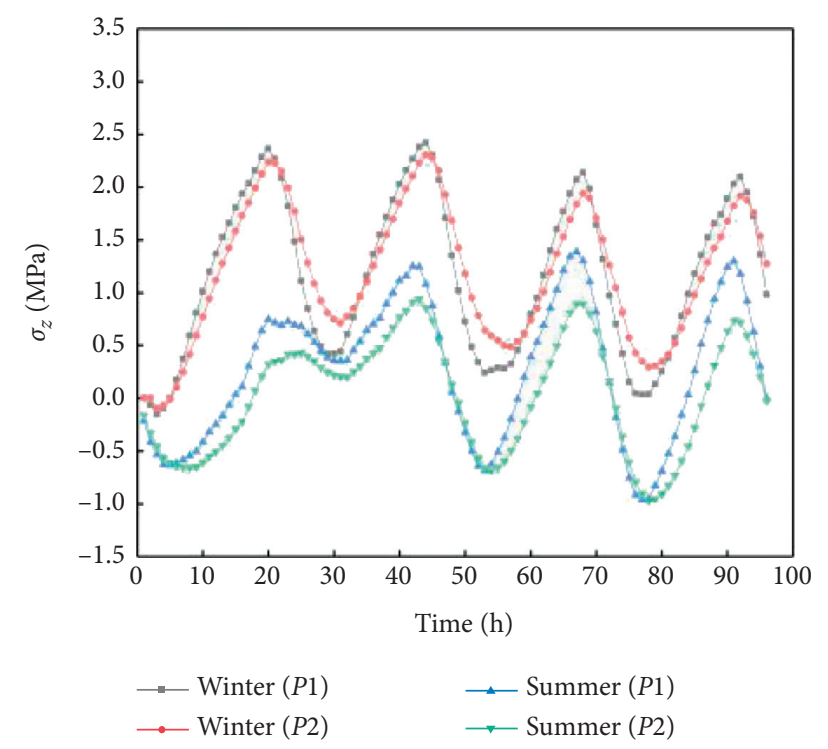

FIGURE 10: Z-direction stress-time curves of two representative points.

TABLE 4: Z-direction stress of two representative points at typical moments.

\begin{tabular}{lcccc}
\hline & Time $(\mathrm{h})$ & External air temperature $\left({ }^{\circ} \mathrm{C}\right)$ & $P 1 \sigma_{z}(\mathrm{MPa})$ & 2.35 \\
\\
\multirow{4}{*}{ Winter } & 20 & 6.6 & 2.40 & 2.20 \\
& 44 & 6.9 & 2.20 & 2.30 \\
& 68 & 8.1 & 2.20 & 1.90 \\
\multirow{3}{*}{ Summer } & 92 & 8.2 & 1.30 & 0.95 \\
& 43 & 17.4 & 1.40 & 0.90 \\
& 67 & 16.1 & 1.30 & 0.75 \\
\hline
\end{tabular}

produced larger tensile stress, which indicated that the temperature variation of concrete was sensitive to the temperature drop. When the diurnal temperature variation was larger, the downstream side of arch dam generated larger tensile stress, about $2.4 \mathrm{MPa}$, and cracks occurred when the tensile stress caused by thermal stress and other loads exceeded the tensile strength of concrete. The measured positions of cracks were basically around the elevation of $1190 \mathrm{~m}$ and $1150 \mathrm{~m}$, almost the same to calculated positions of tensile stress, so it showed that larger diurnal temperature variation was one of the main causes of horizontal cracking at the downstream side of Xiaowan arch dam.

\section{Conclusions}

Based on ANSYS and the self-developed COCE-3D finite element software and adopting the method of combing the integral model and submodel, the sensitivity of element types and mesh scales to the calculation results of thermal field were calculated and analyzed, and the change process of thermal field and thermal stress in three standard dam segments $\left(27^{\#} \sim 29^{\#}\right)$ during typical periods in winter and summer was also analyzed. The conclusions are as follows:
(1) When the same element type and different mesh sizes were used to calculate the thermal field, the mesh size was too large, so that the temperature gradient of concrete surface changed slowly, and the influence depth by temperature was greatly deep. When the high-order element was used for calculation, yet the calculation precision of surface temperature was improved, the precision of the scope of influence had not.

(2) The downstream side of arch dam was greatly affected by the air temperature, especially sensitive to the diurnal temperature variation in winter. The shorter the action time of air temperature, the greater the changes of temperature gradient of dam concrete surface; the longer the action time of air temperature, the greater the influence depth of concrete temperature, but to be kept unchanged after reaching a certain depth. As the air temperature changed, the temperature variation of concrete had different hysteresis effect.

(3) The thermal stress of concrete at downstream side of arch dam was larger, and the change law of thermal stress was basically consistent with that of air temperature. The maximum principal stress 
and $Z$-direction stress were almost the same in direction. When the temperature dropped sharply, the thermal stress was mainly a tensile stress, and when the temperature increases, a compressive stress appeared.

(4) The calculation results of thermal stress was basically consistent with the positions of measured cracks, which indicated that the thermal stress generated by the diurnal temperature variation was one of the important causes of horizontal cracking at the downstream side of Xiaowan arch dam.

(5) The combination of the integral model and submodel is an effective method to study the thermal field and the change law of thermal stress of dam concrete surface, so as to obtain satisfactory results.

\section{Data Availability}

The data used to support the findings of this study are available from the corresponding author upon request.

\section{Conflicts of Interest}

The authors declare that they have no conflicts of interest.

\section{Acknowledgments}

This study was supported by the Special Fund for Scientific Research by Shaanxi Provincial Education Department (20JK0962) and Special Fund for Natural Science Basic Research Program of Shaanxi Province (2021JQ-872).

\section{References}

[1] F. Sheibany and M. Ghaemian, "Effects of environmental action on thermal stress analysis of Karaj concrete arch dam," Journal of Engineering Mechanics, vol. 132, no. 5, pp. 532-544, 2006.

[2] F. Jin, Z. Chen, J. Wang, and J. Yang, "Practical procedure for predicting non-uniform temperature on the exposed face of arch dams," Applied Thermal Engineering, vol. 30, no. 14, pp. 2146-2156, 2010.

[3] F. Salazar, D. J. Vicente, J. Irazábal, I. De-Pouplana, and J. San Mauro, "A review on thermo-mechanical modelling of arch dams during construction and operation: effect of the reference temperature on the stress field," Archives of Computational Methods in Engineering, vol. 27, no. 5, pp. 1681-1707, 2020.

[4] F. Pettersson and F. Hjalmarsson, Finite Element Analysis of Cracking of concrete Arch Dams Due to Seasonal Temperature Variation, Lund University, Lund, Sweden, 2017.

[5] M. Li, W. Si, S. Du, M. Zhang, Q. Ren, and Y. Shen, "Thermal deformation coordination analysis of CC-RCC combined dam structure during construction and operation periods," Engineering Structures, vol. 213, Article ID 110587, 2020.

[6] S. J. Fu, T. He, G. J. Wang, S. H. Zhang, L. C. Zou, and S. H. Chen, "Evaluation of cracking potential for concrete arch dam based on simulation feedback analysis," Science China, vol. 54, no. 3, pp. 565-572, 2011.

[7] B. F. Zhu, "On permanent superficial thermal insulation of concrete arch dams," Water Power, vol. 08, pp. 21-30, 2006.
[8] E. Y. Sayed-Ahmed, A. A. Abdelrahman, and R. A. Embaby, "Concrete dams: thermal-stress and construction stage analysis," Dams and Reservoirs, vol. 28, no. 1, pp. 1-19, 2017.

[9] C. Eloísa, S. Noemí, T. Carlos, and B. F. M. Luísa, "FEA model for the simulation of the hydration process and temperature evolution during the concreting of an arch dam," Engineering Structures, vol. 174, pp. 165-177, 2018.

[10] D. Santillan, E. Salete, and M. A. Toledo, "A methodology for the assessment of the effect of climate change on the thermalstrain-stress behaviour of structures," Engineering Structures, vol. 92, no. 1, pp. 123-141, 2015.

[11] J. Enzell and M. Tollsten, Thermal Cracking of a concrete Arch Dam Due to Seasonal Temperature Variations, Royal Institute of Technology (KTH), Stockholm, Sweden, 2017.

[12] R. Malm, R. Hellgren, and J. Enzell, "Lessons learned regarding cracking of a concrete arch dam due to seasonal temperature variations," Infrastructure, vol. 5, no. 2, pp. 1-18, 2020.

[13] H. Mirzabozorg, M. A. Hariri-Ardebili, and M. Shirkhan, "Impact of solar radiation on the uncoupled transient thermostructural response of an arch dam," Scientia Iranica, vol. 22, no. 4, pp. 1435-1448, 2015.

[14] D. Santillán, E. Salete, D. J. Vicente, and M. Á. Toledo, “Treatment of solar radiation by spatial and temporal discretization for modeling the thermal response of arch dams," Journal of Engineering Mechanics, vol. 140, no. 11, Article ID 05014001, 2014.

[15] G. Liu, "Numerical simulation and anslysis of the temperature effects on the fission of concrete," Thermal Science, vol. 23, no. 5A, pp. 2713-2720, 2019.

[16] L. F. Song, M. X. Wu, J. T. Wang, and Y. J. Xu, "Seismic damage analysis of the outlet piers of arch dams using the finite element sub-model method," Earthquake Engineering and Engineering Vibration, vol. 03, pp. 617-626, 2016.

[17] B. F. Zhu, Temperature Stress and Temperature Control of Mass concrete, China Electric Power Press, Beijing, China, 1999.

[18] The Professional Standards Compilation Group of People's Republic of China, Design Specification for concrete Arch Dams, China Electric Power Press, Beijing, China, 2007.

[19] The Professional Standards Compilation Group of People's Republic of China, Design Specification for concrete Arch Dams, China Electric Power Press, Beijing, China, 2018.

[20] G. F. Hu, Surface Crack Analysis of Xiaowan High Arch Dam during Operation Period, Wuhan University, Wuhan, China, 2016.

[21] X. Zhang, W. M. Wang, and S. H. Chen, "Research on reinforcement measure of embankment cracks of Xiaowan arch dam," Chinese Journal of Rock Mechanics and Engineering, vol. 30, no. 4, pp. 657-665, 2011.

[22] S. J. Fu, S. H. Zhang, M. Xie, and S. H. Chen, "Dynamic analysis theory and practice for temperature control and cracking prevention of concrete arch dam," Chinese Journal of Rock Mechanics and Engineering, vol. 31, no. 1, pp. 113-122, 2012.

[23] H. H. Zhang, P. Z. Wang, S. H. He, Y. Li, K. F. Chen, and N. N. Sun, "Research of thermal effect of cable-stayed bridge with a separated side-box steel-concrete composite girder under solar radiation," Advances in Civil Engineering, vol. 2021, Article ID 8812687, 17 pages, 2021.

[24] S. R. Abid, N. Tayşi, and M. Ozakca, "Temperature records in concrete box-girder segment subjected to solar radiation and air temperature changes," IOP Conference Series: Materials Science and Engineering, vol. 870, no. 1, Article ID 012074, 2020.

[25] B. Gu, Z. J. Chen, and X. D. Chen, "Temperature gradients in concrete box girder bridge under effect of cold wave," Journal of Central South University, vol. 21, no. 3, pp. 1227-1241, 2014. 